\title{
Saline-immersion therapeutic endoscopy (SITE) combined with endoscopic submucosal dissection (ESD) of a rare cause of intussusception: a giant Brunner gland adenoma
}

A 48-year-old woman was referred to our institution due to abdominal pain and an episode of melena. At esophagogastroduodenoscopy (EGD) an 60-mm pedunculated lesion (Paris $0-\mathrm{Ip}$ ) was identified. The lesion was arising from the duodenal aspect of the pyloric ring ( Fig. 1, > Fig.2) and prolapsing into D3. Computed tomography showed duodenal thickening with areas of fat tissue that could represent a lipoma or a liposarcoma. A scheduled therapeutic EGD was performed under general anesthesia with surgical backup on standby. The scope was retroflexed in the bulb to ensure direct visualization of the lesion's stalk and saline-immersion therapeutic endoscopy (SITE)-facilitated endoscopic submucosal dissection (ESD) was performed ( $>$ Fig. $\mathbf{3}$, \ Video $\mathbf{1}$ ). After resection, tip-of-the-knife coagulation was applied prophylactically to cauterize any visible vessels. No intraprocedural or postprocedural complications occurred. Histopathological analysis revealed a Brunner gland adenoma (BGA) without any evidence of dysplasia or malignant components ( $\mathbf{F i g . 4 , ~}$ - Fig. $\mathbf{5}$ ); sections of the polyp showed nodules of Brunner glands in the submucosa and extending into the underlying adipose tissue. These findings were in keeping with a diagnosis of a giant BGA measuring $60 \times 34 \times 24 \mathrm{~mm}$.

BGAs are very rare benign duodenal tumors proliferating from normal Brunner glands. BGAs represent about 5\%-10\% of benign duodenal tumors and have an estimated incidence of less than $0.01 \%$ $[1,2]$. Patients are usually asymptomatic and these lesions can present as incidental findings during EGD or imaging. Nonspecific gastrointestinal symptoms including abdominal pain, nausea, and bloating have been reported. Gastrointestinal bleeding, iron deficiency anemia, and obstructive symptoms have also been described in rare cases $[3,4]$.

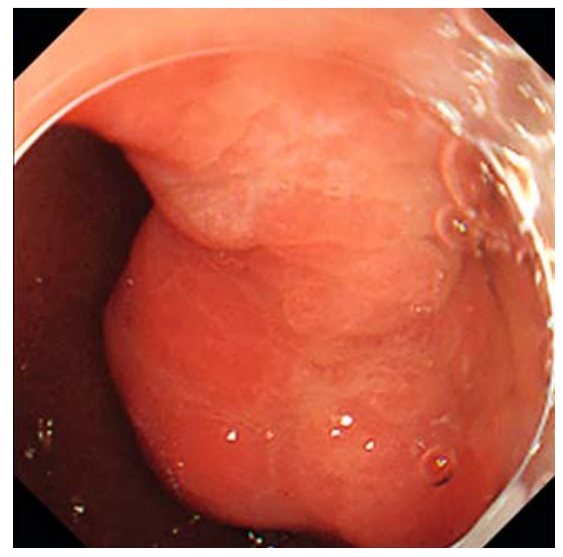

- Fig. 1 Pedunculated lesion arising from the pyloric ring in a 48-year-old woman referred because of abdominal pain and melena.

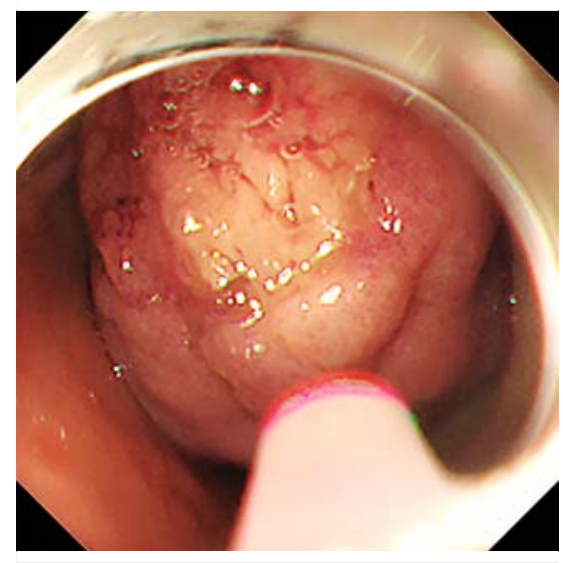

Fig. 2 Saline-immersion therapeutic endoscopy (SITE) facilitated endoscopic submucosal dissection (ESD).
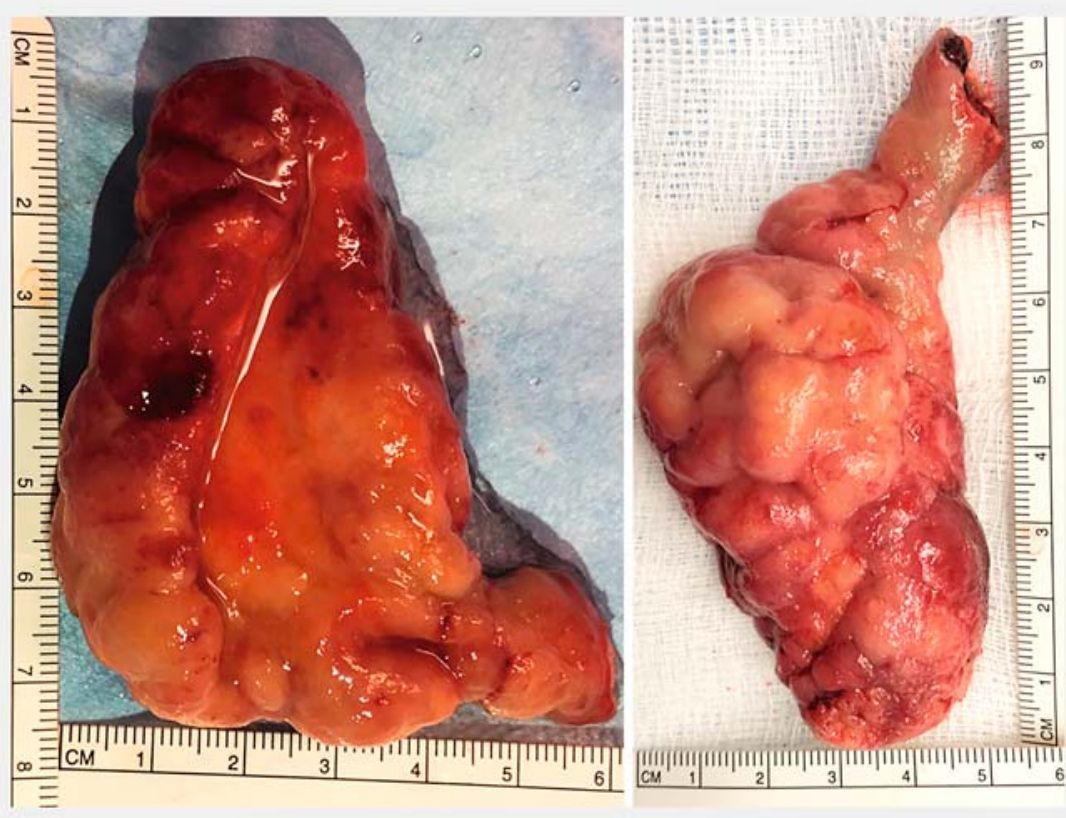

Fig. 3 The retrieved specimen.

To date, a consensus for the optimal management of giant BGA is lacking. Surgical and endoscopic management have been reported depending on lesion size and local expertise. Careful endoscopic resec- tion appears to be effective, minimally invasive, and safe even for giant lesions.

Endoscopy_UCTN_Code_TTT_1AO_2AG 


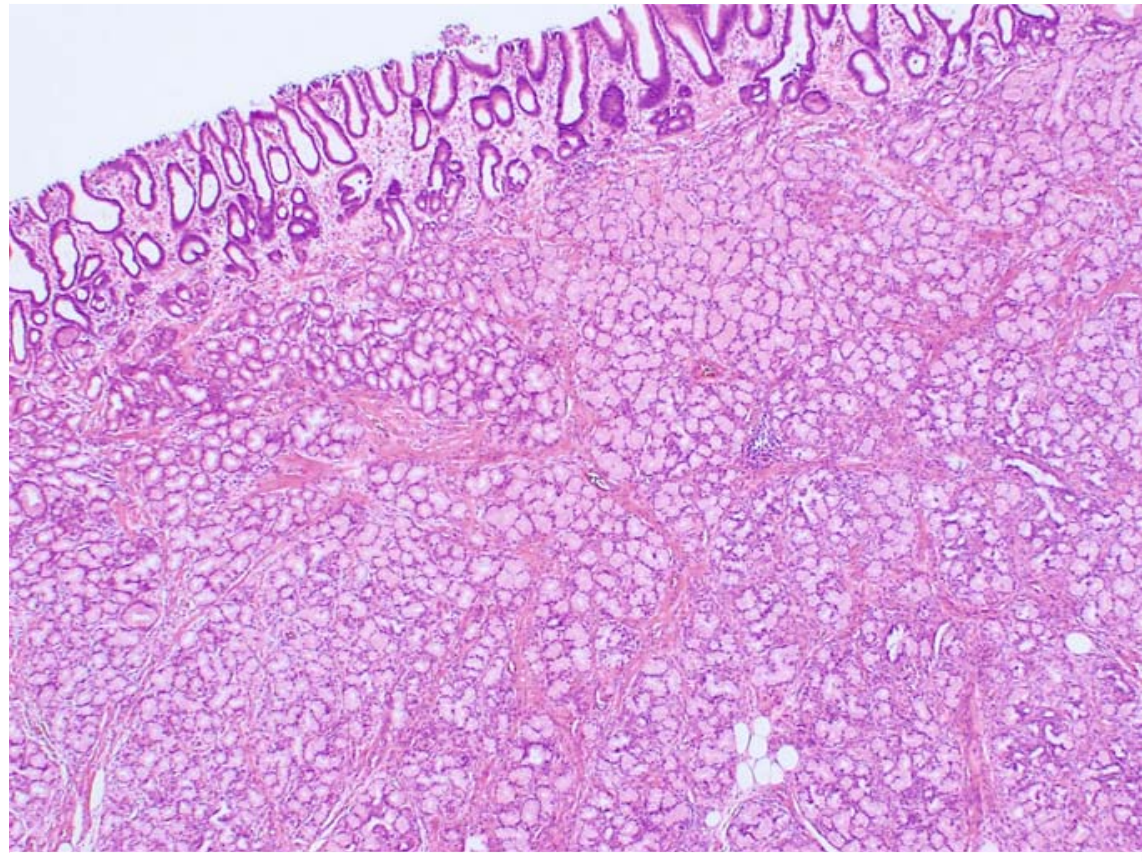

- Fig. 4 Histopathology image showing no evidence of dysplasia or malignant components.

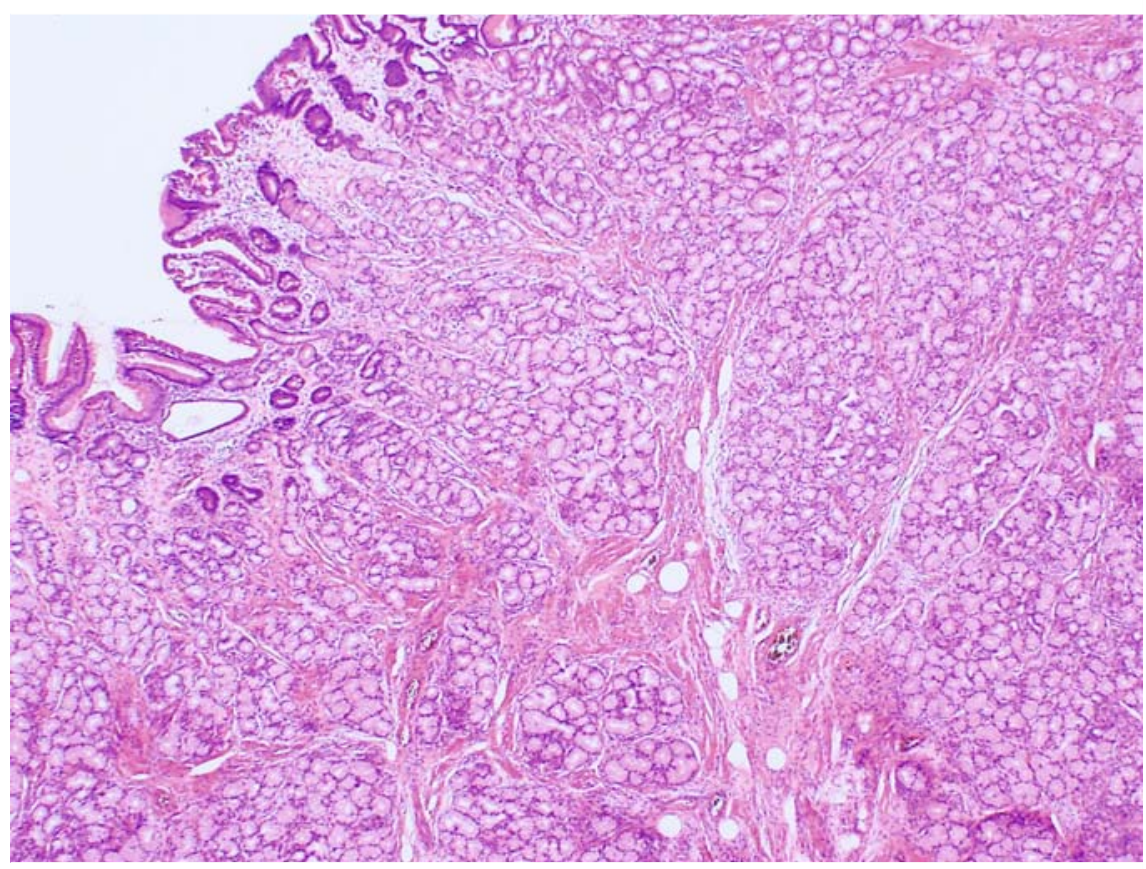

- Fig. 5 Histopathology image showing nodules of Brunner glands in the submucosa and extending into the underlying adipose tissue.
Acknowledgements

We wish to thank our colleague, Dr. Jennifer Watkins, consultant cellular pathologist, for her kind input into this case.

\section{Competing interests}

Dr. Despott and Dr. Murino receive research/ education support from Aquilant Medical, Fujifilm, Olympus, and Pentax Medical. Professor Yano receives research/education support from Fujifilm. All other authors have no conflict of interest to disclose.

The authors

Nikolaos Lazaridis' ${ }^{1}$, Alberto Murino ${ }^{1}$, Filippos Solonos ${ }^{1}$, Eftychia Athanasiadou ${ }^{1}$, Alice Podesta ${ }^{1}$, Tomonori Yano ${ }^{1,2}$, Edward J. Despott $^{1}$

1 Royal Free Unit for Endoscopy, The Royal Free Hospital and University College London (UCL) Institute for Liver and Digestive Health, London, United Kingdom

2 Division of Gastroenterology, Department of Medicine, Jichi Medical University, Shimotsuke, Japan

Corresponding author

\section{Edward J. Despott, MD, FRCP}

The Royal Free Hospital and University College London (UCL) Institute for Liver and Digestive Health, Pond Street, Hampstead, London, NW3 2QG, United Kingdom

Fax: +44-20-74315261

edespott@doctors.org.uk

\section{References}

[1] Botsford TW, Crowe P, Croker DW. Tumors of the small intestine. A review of experience with 115 cases including a report of a rare case of malignant hemangioendothelioma. Am J Surg 1962; 103: 358-365

[2] Rocco A, Borriello P, Compare D et al. Large Brunner's gland adenoma: case report and literature review. World J Gastroenterol 2006; 12: 1966-1968

[3] Marinacci LX, Manian FA. Brunner gland adenoma. Mayo Clin Proc 2017; 92: 17371738

[4] Liang HH, Wei PL, Wang W et al. A rare cause of duodenal obstruction. Gut 2008; 57 : 1385,1397 


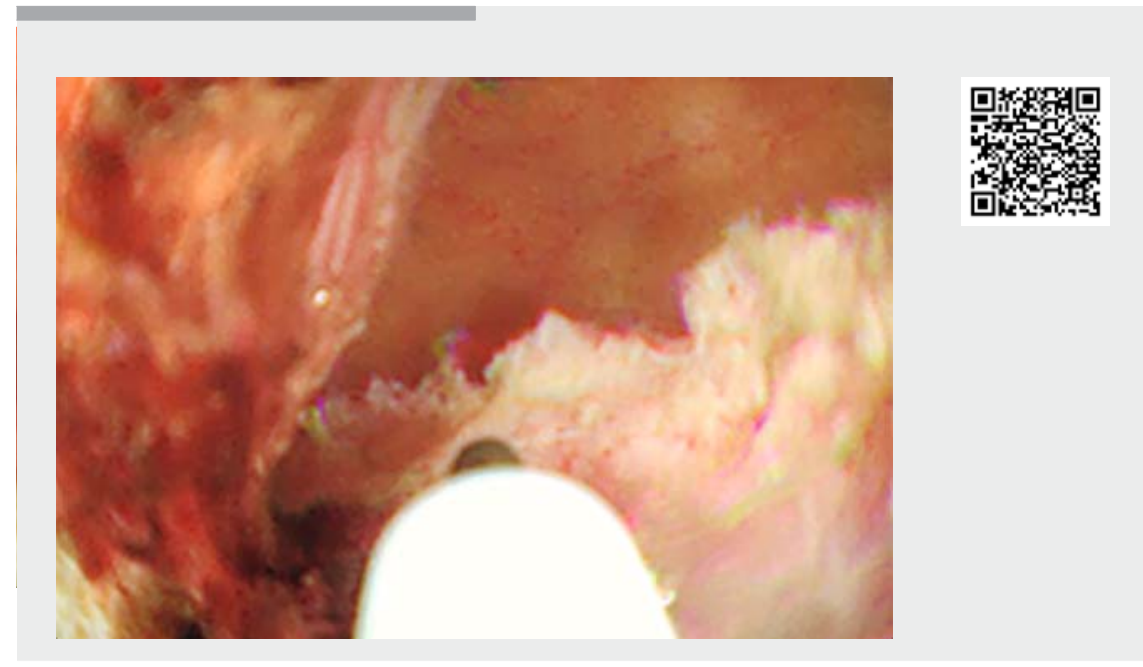

Video 1 Saline-immersion therapeutic endoscopy (SITE) facilitated endoscopic submucosal dissection (ESD) of a giant Brunner gland adenoma.

\section{Bibliography}

Endoscopy 2021; 53: E62-E64

DOI 10.1055/a-1187-0625

ISSN 0013-726X

published online 19.6.2020

(c) 2020. Thieme. All rights reserved.

Georg Thieme Verlag KG, Rüdigerstraße 14,

70469 Stuttgart, Germany

\section{ENDOSCOPY E-VIDEOS \\ https://eref.thieme.de/e-videos}

口回 Endoscopy E-Videos is a free Fing 自䢂: on interesting cases and new techniques in gastroenterological endoscopy. All papers include a high quality video and all contributions are freely accessible online.

This section has its own submission website at

https://mc.manuscriptcentral.com/e-videos 